\title{
Desigualdades habitacionais no "repovoamento" do centro expandido do município de São Paulo
}

\author{
Housing inequalities in the "repopulation" of the expanded \\ downtown area of the municipality of São Paulo
}

Anderson Kazuo Nakano

\begin{abstract}
Resumo
0 presente artigo discute o tão almejado "repovoamento" do centro expandido do município de São Paulo, ocorrido entre os anos 2000 e 2010 e impulsionado pela lógica mercantil vigente na urbanização capitalista. Analisa os dados relativos à produção imobiliária voltada para compradores de média e alta renda em detrimento das demandas da população de baixa renda. Esta última se insere nas tendências de "repovoamento" buscando acessar moradias em cômodos, cortiços e assentamentos precários. Ademais, o artigo mostra que, a despeito do "repovoamento" e da inversão demográfica ocorrida no centro expandido paulistano, houve a persistência do crescimento populacional na periferia, embora em ritmo lento, mantendo os níveis de desigualdades de renda domiciliar que marcam o modelo centro-periferia.
\end{abstract}

Palavras-chave: desigualdade habitacional; repovoamento; centro expandido; São Paulo.

\begin{abstract}
This article discusses the long-awaited "repopulation" of the expanded downtown area of the municipality of São Paulo, which occurred between the years 2000 and 2010, driven by the mercantile logic of the capitalist urbanization. It analyzes data on real estate production aimed at medium- and high-income buyers at the expense of the demands of the low-income population. The latter is inserted in "repopulation" trends, seeking to access dwellings in slums and precarious settlements. In addition, the article shows that, in spite of the "repopulation" and demographic inversion that took place in the expanded downtown area of São Paulo, the population continued to grow in the periphery, albeit at a slow pace, maintaining the levels of household income inequalities that mark the center-periphery model.
\end{abstract}

Keywords: housing inequality; repopulation; expanded downtown area; São Paulo. 


\section{Introdução}

As reduções nos números de moradores dos distritos do centro expandido ${ }^{1}$ do município de São Paulo, ocorridas nas décadas de 1980 e 1990, foram amplamente criticadas por urbanistas, gestores públicos e movimentos sociais, dentre outros setores. Um dos pontos principais enunciado nessas críticas apontava para os desperdícios ocasionados pelo chamado "esvaziamento" daquele centro expandido. Essa parte privilegiada do município de São Paulo é reconhecida, dentre outros fatores, por seus bairros residenciais das camadas de alta renda; pelas boas provisões de serviços, equipamentos e infraestruturas urbanas; pela grande oferta de oportunidades de emprego, principalmente no setor de serviços e comércio; pelas diversas possibilidades de lazer, consumo e cultura; dentre outros fatores.

De acordo com aquele argumento crítico, o "esvaziamento" do centro expandido paulistano era visto como um processo que levava à subutilização e a um baixo aproveitamento de espaços urbanos bem localizados e constituídos por todos aqueles atributos positivos produzidos por grande quantidade de investimentos públicos e privados realizados ao longo da história da cidade.

Outra crítica relativa àquele mesmo fenômeno ligado ao "esvaziamento" do centro expandido paulistano apontava para o agravamento dos problemas de mobilidade urbana gerado pelo distanciamento entre os locais de trabalho, concentrados majoritariamente naquele centro expandido, e os locais de moradia dos trabalhadores. Tanto esse distanciamento quanto os problemas de mobilidade urbana dele decorrentes já existiam por causa da estrutura centro-periferia produzida pela urbanização paulistana ao longo da segunda metade do século $X X$.

A crítica mencionada no parágrafo anterior apontava para o fato de que a saída de moradores do centro expandido se associava ao crescimento urbano e populacional das áreas periféricas impulsionadas pela expansão e adensamento urbano de bairros populares e pela implantação de condomínios residenciais destinados às camadas de média e alta renda. Em geral, os moradores desses bairros são forçados a buscar trabalho em locais distantes, pois a maior parte das áreas periféricas da cidade de São Paulo não conta, até hoje, com ofertas insuficientes de oportunidades de trabalho, emprego e geração de renda. Com isso, os moradores antigos e recentes desses bairros periféricos de baixa, média e alta renda seguem diariamente para o centro expandido sofrendo com os congestionamentos de ruas e avenidas atravancados por automóveis individuais privados e com a superlotação dos sistemas de transporte coletivo.

Com base naquelas críticas surgiram, na década de 1990, alertas, reivindicações e ações políticas encaminhadas por movimentos populares, urbanistas, gestores públicos e organizações sociais, dentre outros sujeitos, que defendiam a adoção de políticas públicas, principalmente urbanas e habitacionais, capazes de promover o "repovoamento" do centro expandido do município de São Paulo. As ações políticas mais contundentes foram realizadas pelos movimentos de luta por moradia que passaram a ocupar prédios ociosos localizados nas partes mais antigas do centro de São Paulo a partir de meados da década de 1990. Na década 
de 2000, essas ocupações de prédios ociosos continuaram ocorrendo expondo os conflitos sociais inseridos no "repovoamento" daquele centro expandido.

Em que pese a importância de algumas realizações pontuais voltadas para a provisão de habitação de interesse social, realizadas principalmente a partir do ano 2000 pelos governos do município e do estado de São Paulo, não se pode dizer que houve a implementação de políticas públicas em larga escala que promovesse o "repovoamento" do centro expandido do município de São Paulo. Tampouco houve políticas públicas que promovessem tal "repovoamento" com a inclusão social e territorial das camadas populares de baixa renda nos benefícios existentes nas áreas mais bem providas de serviços, equipamentos e infraestruturas urbanas da cidade.

No entanto, mesmo sem a indução de políticas urbanas e habitacionais sócio e territorialmente inclusivas, o "repovoamento" do centro expandido do município de São Paulo ocorreu na década entre os anos de 2000 e 2010. Por isso, os grupos sociais de menor renda que, muitas vezes, sobrevivem imersos na pobreza e em diversas situações de vulnerabilidade social, urbanística, econômica e ambiental, não puderam contar com acessos a moradias adequadas em quantidade suficiente nas porções centrais e intermediárias da cidade de São Paulo, onde estão as áreas com maior oferta de oportunidades de trabalho e melhor provisão de serviços, equipamentos e infraestruturas urbanas.

Como resultado de todo esse processo, nota-se a existência de profundas desigualdades habitacionais associadas a esse "repovoamento" do centro expandido. 0 presente artigo tem como objetivo analisar algumas características dessas desigualdades a partir dos microdados dos censos demográficos 2000 e 2010 do IBGE. Ademais, o presente artigo enfatiza a necessidade de políticas, ações, investimentos e estratégias mais efetivas para a promoção e produção de habitação de interesse social nesse centro expandido que não se estruturem exclusivamente segundo a lógica mercantil, como ocorreu nos atendimentos habitacionais realizados em diferentes momentos da história do Brasil, inclusive no recente Programa Minha Casa Minha Vida (PMCMV).

A realização dessa discussão é importante porque, apesar de ser óbvio o fato de que uma política pública deva priorizar o atendimento das necessidades dos segmentos mais empobrecidos e vulneráveis da sociedade, no setor habitacional é cada vez mais comum ver a subordinação desse atendimento a interesses de agentes privados do mercado imobiliário que almejam principalmente a obtenção de lucros a partir da renda fundiária. É notória a ocorrência de parcerias entre aqueles agentes empresariais do mercado imobiliário privado e o poder público na promoção e produção de habitação de interesse social que, muitas vezes, resultam em produtos inadequados do ponto de vista urbanístico, arquitetônico e ambiental. ${ }^{2}$

É sabido que a lógica mercantil no atendimento às necessidades habitacionais, centrada na produção e comercialização da propriedade privada individualizada, não atende às necessidades habitacionais das populações de baixa renda em localizações bem servidas por serviços, equipamentos e infraestruturas urbanas básicas e onde os preços de imóveis são mais altos. ${ }^{3}$ Daí a importância de atendimentos habitacionais pautados por modos inovadores 
de provisão pública de moradias adequadas que incluam novos canais de acesso às unidades produzidas e novos regimes de propriedade imobiliária, definidos a partir do valor de uso e da efetivação do direito à moradia digna ao invés de priorizar o valor de troca. ${ }^{4}$

\section{A Constituição do centro expandido na estruturação urbana do município de São Paulo}

Sabe-se que a vinda dos imigrantes estrangeiros, no final do século XIX e na primeira metade do século XX para o município de São Paulo, teve forte ligação com a estruturação do "lado de lá" e do "lado de cá" nos espaços intraurbanos paulistanos. Segundo Villaça (2001), a "expansão para oeste era bem mais vantajosa que para leste. Assim, as classes de mais alta renda se expandiram para oeste e as de mais baixa renda e as indústrias, para leste" (Villaça, 2001, p. 193). Desde então, a cidade de São Paulo passou a contar com "o lado de lá" visto como o território popular dos imigrantes operários, correspondente à atual Zona Leste, e "o lado de cá" tido como a parte mais rica e próxima dos comércios e serviços sofisticados do centro principal e, atualmente, reconhecido como o centro expandido do município de São Paulo.

Na primeira metade do século $X X, 0$ "lado de lá" foi constituído pelas localizações situadas para além da antiga estrada de ferro Santos-Jundiaí ${ }^{5}$ e do rio Tamanduateí e de sua problemática várzea inundável (várzea do Carmo). Trata-se de áreas dos atuais distritos Brás, Pari, Mooca e Belém que foram ocupadas pelas instalações das primeiras indústrias paulistanas implantadas junto aos bairros ocupados com comércios e moradias destinadas a trabalhadores e operários de baixa renda vindos da Itália, Espanha e Portugal, dentre outros países europeus. Sabe-se que muitos desses trabalhadores e operários vieram também das fazendas de café do interior paulista que, dadas as condições extremamente precárias de vida e de trabalho lá existentes, fugiram para a cidade de São Paulo.

As indústrias instaladas nos grandes terrenos planos localizados junto à ferrovia Santos-Jundiaí e próximos ao rio Tamanduateí deram início à formação da vasta Zona Leste, conhecida historicamente pela presença de centenas de bairros populares que surgiram para abrigar, a partir de meados do século XX, os milhões de migrantes de baixa renda vindos de outras partes do País, em especial dos estados nordestinos.

Já o "lado de cá" se identificou mais com as porções mais centrais da cidade de São Paulo que, na primeira metade do século $X X$, se referia respectivamente às áreas comerciais e de serviços localizadas nos atuais distritos Sé e República. Identificou-se também com os bairros formados pelas moradias das camadas de alta renda e pelos estabelecimentos comerciais dos imigrantes vindos de países europeus, que foram viver no atual distrito Bom Retiro, e asiáticos, em especial do Japão, que se instalaram no atual distrito Liberdade.

0 centro paulistano, com o famoso triângulo histórico formado pela rua Direita, São Bento e 15 de Novembro, concentrava o comércio sofisticado do começo do século XX. 0 centro novo daquela época foi constituído após a transposição do córrego Anhangabaú, 
encaixado no fundo do vale com o mesmo nome, que era mais estreito e menos problemático do que o mencionado rio Tamanduateí e sua respectiva várzea inundável. Nesse centro novo formado nos arredores da atual praça da República se concentraram tanto comércios, serviços e prédios de escritórios modernos quanto bairros ocupados com as moradias de paulistas, paulistanos e imigrantes de alta renda, como Campos Elíseos, Santa Ifigênia, Vila Buarque, Santa Cecília e Higienópolis.

Ao descrever o trajeto de formação desses bairros das camadas de alta renda, Villaça (2001, p. 195) diz que ele continuou

a crescer na direção oeste, na rua São João em Santa Cecília; todo o trecho entre a atual Praça Marechal Deodoro e o Parque da Água Branca (hoje Fernando Costa) foi tomado por palacetes, no início do século $(X X)$. Mas a direção oeste tinha sítio claramente menos atraente que a sudoeste, onde os sítios altos e ondulados levavam aos contrafortes do divisor de águas (espigão da avenida Paulista), o ponto culminante da região. A aristocracia paulistana fez então uma deflexão à esquerda e, através da Vila Buarque e Higienópolis, chegou à avenida Paulista, aberta em 1892.

Com tal deflexão, aqueles bairros das camadas de alta renda logo se expandiram ocupando os contrafortes do chamado "espigão da avenida Paulista" voltados para aquele centro novo, formando os bairros da Consolação, Pacaembu e Cerqueira César. Porém, no momento em que esses bairros atingiram o cume daquele espigão, divisor das várzeas dos dois principais rios que atravessam a cidade de São Paulo, o Tietê e o Pinheiros, ocorre algo que contradiz a ideia de que os grupos de mais alta renda sempre procuram os sítios mais elevados e com os maiores atrativos naturais para erigir seus bairros de moradia.

De acordo com Villaça (ibid., p. 197), uma vez atingido aquele ponto culminante, "a aristocracia não procurou ocupá-lo em toda a sua extensão". Para ele, isso mostra que o sítio não é o único determinante da localização dos bairros das camadas sociais endinheiradas, pois se

o sítio fosse a principal razão de sua implantação, a burguesia teria ocupado, depois da avenida Paulista, o restante do espigão, localizando-se nas áreas hoje ocupadas pela rua Domingos de Moraes e pela avenida Dr. Arnaldo (nas direções da Vila Mariana e do alto Sumaré, respectivamente). (Ibid.)

Villaça afirma ainda que, ao invés de se estenderem ao longo do topo do espigão da Paulista, os bairros das camadas de alta renda paulistanas buscaram, surpreendentemente,

os terrenos planos, insípidos, pantanosos e de pouca resistência física da baixada do rio Pinheiros, produzindo ali, na segunda década do século (XX), o Jardim América. Também nessa mesma baixada surgiriam, algumas décadas depois, os loteamentos do Jardim Europa, Alto de Pinheiros e City Butantã, igualmente destinados àquela classe e igualmente em sítios planos e sem atrativo. (lbid.)

Com isso, ocorreu a ocupação dos contrafortes do "espigão da Paulista" voltados para o rio Pinheiros dando origem aos conhecidos bairros Jardins (Europa, América e Paulista). Esses bairros de baixa densidade urbana, formados por mansões e palacetes construídos em grandes lotes ajardinados e acessados a partir de ruas intensamente arborizadas, abrigavam 
os ricos empresários, comerciantes, profissionais liberais, industriais e fazendeiros da época e, podemos dizer, continuam abrigando os grupos mais endinheirados dos dias atuais.

Como já mencionado anteriormente, a consolidação desse vetor centro-sudoeste como o vetor dos bairros das camadas de alta renda nos espaços intraurbanos paulistanos foi acompanhada pela consolidação de áreas comerciais destinadas ao consumo caro, bem como pela implantação dos mais importantes equipamentos culturais, de serviços e de lazer da cidade e pela instalação de boa parte das instituições públicas de diferentes níveis de governo, principalmente municipais e estaduais. Com isso se constituiu o atual centro expandido do município de São Paulo cujo "repovoamento", associado a desigualdades habitacionais, analisa-se e discute-se no presente artigo.

\section{Entre o esvaziamento e o repovoamento do centro expandido do município de São Paulo}

Para comprovar a mudança das tendências de "esvaziamento" populacional para a de "repovoamento" nas áreas centrais da cidade de São Paulo, basta observar as taxas médias de crescimento anual dos 96 distritos oficiais calculadas a partir de dados censitários para os períodos entre 1991 e 2000 e entre 2000 e 2010.

0 esvaziamento populacional nas áreas centrais e o crescimento periférico de São Paulo ocorrido nas décadas de 1980 e 1990 já foram discutidos por Januzzi e Januzzi (2002), na escala do município de São Paulo, e por
Torres (2005), na escala da região metropolitana de São Paulo. Esses autores mostraram que as baixas taxas médias de crescimento anuais registradas nessas unidades territoriais durante aquelas décadas ${ }^{6}$ encobriam a heterogeneidade das tendências demográficas em curso nas diferentes porções dos seus territórios e espaços intraurbanos.

A Figura 1 mostra claramente o esvaziamento populacional ocorrido nos distritos localizados no centro expandido do município de São Paulo, no período entre 1991 e 2000, em contraste com o crescimento nos distritos periféricos. Vale dizer que, naquele período, o crescimento periférico correspondeu a praticamente todo o crescimento populacional municipal.

Essas tendências mudaram significativamente no período entre 2000 e 2010, quando se observou a acentuação no arrefecimento do crescimento populacional paulistano, com taxa média de crescimento anual de $0,8 \%$ para o município de São Paulo como um todo. Essa baixa taxa de crescimento populacional também escondeu múltiplas tendências demográficas que, em comparação com a década de 1990, tiveram alterações bastante significativas.

Na década de 2000, nota-se que, dos 52 distritos que estavam perdendo população na década de 1990, 38 passaram a ganhar moradores, conforme se pode observar na Figura 2. Trata-se de distritos localizados no centro expandido que registraram uma inversão demográfica que convive com a persistência do crescimento periférico. Assim, diferentemente da década de 1990, o crescimento municipal paulistano da década de 2000 contou predominantemente com a contribuição dos 
Figura 1 - Taxa geométrica de crescimento anual segundo distritos do MSP 1991 a 2000

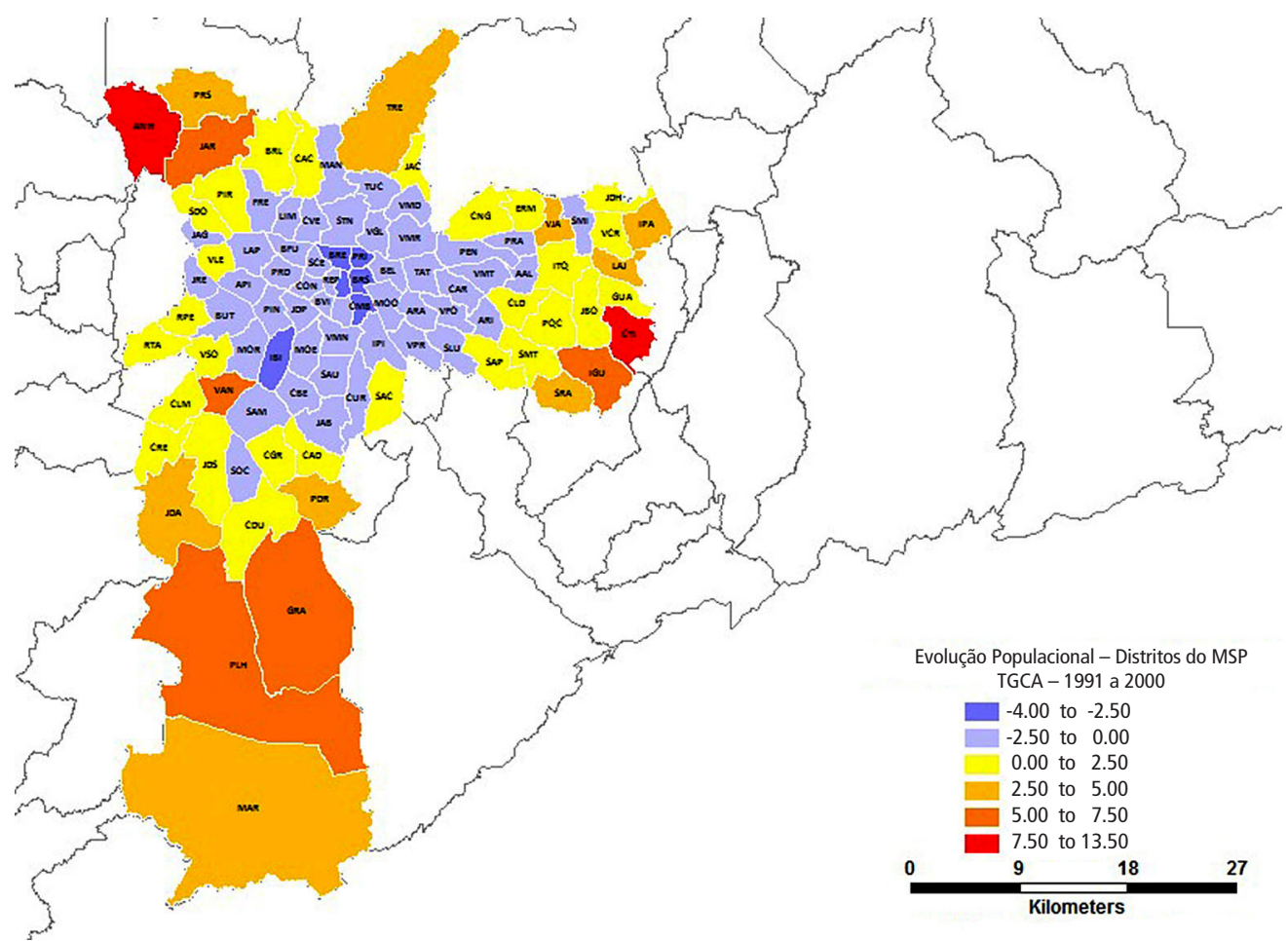

Fontes: Censos demográficos IBGE de 1991 e 2000.

aumentos de moradores ocorridos tanto no centro expandido quanto nas áreas periféricas.

A redistribuição espacial da população paulistana ocorrida na década de 2000 provocou uma série de efeitos sociodemográficos, socioeconômicos e sociourbanísticos que ainda demanda estudos mais detalhados. Ao atualizarem a discussão sobre o "crescimento demográfico intraurbano na região metropolitana de São Paulo" para o período entre 2000 e 2010, Marques e Requena lançaram mão de dados agregados segundo as áreas de ponderação do IBGE, a fim de relativizar a afirmação de que "o centro voltou a crescer"
(PMSP, 2011 apud Marques e Requena, 2015, p. 148), enunciada em nota da Prefeitura Municipal de São Paulo (PMSP) elaborada a partir de dados agregados segundo os 96 distritos oficiais. Para eles

"[...] essa afirmação é ao mesmo tempo verdadeira - pois áreas do centro expandido voltaram a crescer - e bastante incompleta, pois não apenas uma parte da área central continuou a perder população na década de 2000, como também áreas das periferias passaram a se esvaziar, enquanto outras continuam crescendo intensamente, embora em patamar baixo". (Ibid.) 
Figura 2 - Taxa geométrica de crescimento anual segundo distritos do MSP 2000 a 2010

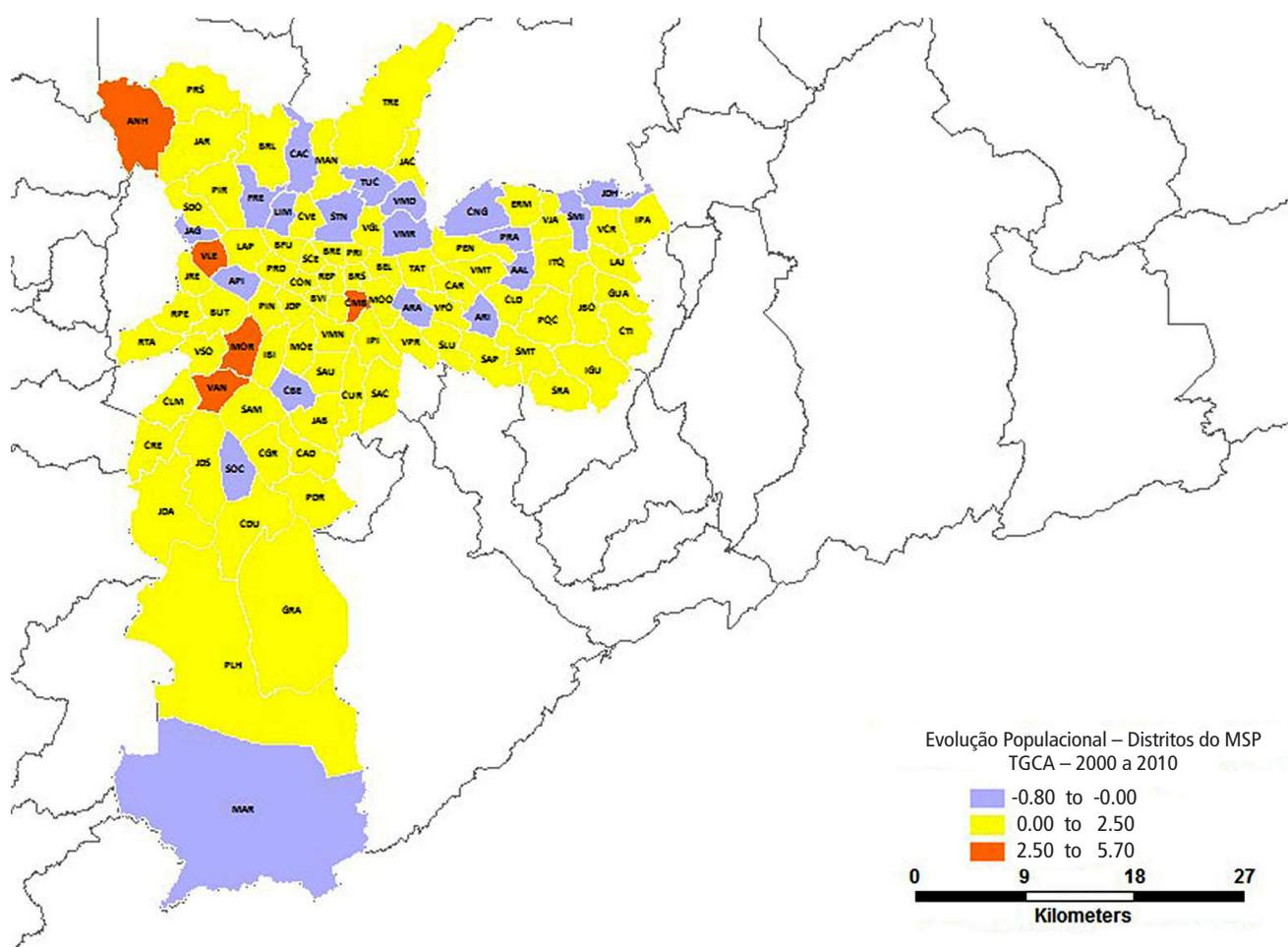

Fontes: Censos demográficos IBGE de 2000 e 2010.

Cotejando os mapas com as taxas de crescimento populacional segundo os distritos paulistanos, apresentados adiante, e as áreas de ponderação da metrópole paulistana, apresentado no trabalho de Marques e Requena (2015, p. 154), percebe-se que alguns distritos do centro expandido que tiveram "repovoamento", como, por exemplo, Jabaquara, Moema, Perdizes, Pinheiros, Saúde, Tatuapé e Vila Formosa, possuíam áreas de ponderação que perderam moradores entre 2000 e 2010.

As diferenças nas tendências demográficas nas áreas de ponderação de um mesmo distrito não invalidam a análise dessas tendências a partir de dados agregados segundo os distritos oficiais do município de São Paulo. Ambas as agregações nos permitem perceber que, na década de 2000:

- ocorreu crescimento populacional na maior parte do centro expandido do município de São Paulo, invertendo as tendências de decrescimento verificadas na década de 1990;

- ocorreu redução populacional em algumas áreas das porções intermediárias da cidade, principalmente a norte e a leste do centro expandido; 
- ocorreu continuidade do aumento de moradores na maior parte das áreas periféricas norte, sul, leste e oeste do município de São Paulo;

- ocorreu redução populacional em algumas (poucas) áreas da periferia paulistana nos distritos de Jaguara, São Miguel, Jardim Helena, Cachoeirinha e Marsilac.

Diante desse quadro, Marques e Requena (ibid.) definiram três conjuntos de áreas de ponderação da Região Metropolitana de São Paulo com diferentes trajetórias demográficas: "a) áreas que decresceram até 2000 e cresceram significativamente na última década; b) áreas que decresceram nas duas décadas; $c$ ) áreas que cresceram intensamente nas duas décadas" (p. 161).

Em relação às áreas de ponderação da metrópole paulistana que perderam população na década de 1990 e tiveram crescimento demográfico, segundo taxas acima de 2,5\% ao ano, localizadas majoritariamente no centro expandido do município de São Paulo, os autores destacaram a presença de: pessoas com maiores rendimentos; de proporção significativa de domicílios em apartamentos; maiores proporções de idosos (com mais de 65 anos de idade) e de empregadas domésticas (que residiam em seus locais de trabalho); e quantidade menor de adolescentes, bem como de pretos e pardos.

Eles viram que "a proporção de domicílios em apartamentos era de 54\% em 2000 e cresceu seis pontos percentuais em 2010, sugerindo que ao menos uma parte do crescimento verificado esteve associada a lançamentos residenciais verticais recentes" (ibid., p. 163). Viram também que "a renda média cresceu bem mais do que a média das demais áreas de ponderação da metrópole" (ibid., p. 164) e que a importância dos migrantes naquela inversão da trajetória demográfica.

Em relação às áreas de ponderação da metrópole paulistana que perderam população tanto na década de 1990 quanto na de 2000, caracterizando a redução populacional persistente, Marques e Requena destacaram, de um lado, a maior presença de idosos e de pessoas com rendimentos menores do que nas áreas anteriores e, de outro lado, a menor presença de crianças e adolescentes. Afirmaram que aquelas áreas com redução populacional persistente "perderam rendimentos em termos relativos [...] não houve concentração específica de produção imobiliária formal [...] tenderam a perder moradores de favelas [...] receberam menos migrantes do que as demais [áreas]" (ibid., pp. 165-166).

Em relação às áreas de ponderação da metrópole paulistana que tiveram crescimento demográfico contínuo nas duas últimas décadas, em especial aquelas que registraram taxas médias de crescimento maiores do que $3 \%$ ao ano na década de 1990 e maiores do que 2,5\% na década de 2000, Marques e Requena (ibid.) destacaram a presença significativa de pessoas com baixa renda, crianças, adolescentes e de domicílios em casas. Chamaram a atenção para a existência de precariedades no acesso à infraestrutura urbana e para a pouca presença de idosos naquelas áreas com crescimento populacional contínuo.

Os autores afirmaram que as áreas de ponderação localizadas nas periferias da mancha urbana metropolitana com crescimento populacional contínuo eram similares às áreas de "fronteira urbana" analisadas por Torres 
(2005), inclusive no que dizia respeito à forte associação com a migração recente. Para eles, a maioria daquelas áreas é "pobre, menos dotada de infraestrutura, continua recebendo migrantes recentes e se localiza em áreas periféricas (Marques e Requena, 2015, p. 170).

Voltando às áreas de ponderação da metrópole paulistana que perderam população na década de 1990 e tiveram crescimento demográfico segundo taxas acima de 2,5\% ao ano, localizadas majoritariamente no centro expandido do município de São Paulo, Marques e Requena (ibid.) não analisaram aspectos relacionados com a desigualdade habitacional associada a esse processo de "repovoamento". Assim, no presente artigo, propõe-se o desenvolvimento de análises a respeito dessa desigualdade habitacional associada ao "repovoamento" daquele centro expandido. Para isso, propõe-se estabelecer os seguintes agrupamentos distritais:

Grupo 1 - distritos ${ }^{7}$ de áreas intermediárias da cidade que perderam moradores tanto na década de 1990 quanto na de 2000 - denominado "esvaziamento persistente";

Grupo 2 - distritos ${ }^{8}$ do centro expandido que perderam moradores na década de 1990 e passaram a ganhá-los na década de 2000 - denominado "repovoamento" e inversão demográfica;

Grupo 3 - distritos ${ }^{9}$ das áreas periféricas que ganharam moradores tanto na década de 1990 quanto na de 2000 - denominado "periferização" 10 persistente;

Grupo 4 - distritos ${ }^{11}$ de bordas urbanas que ganharam moradores na década de 1990 e passaram a perdê-los na década de 2000 - denominado "esvaziamento periférico".
0 Grupo 1 do esvaziamento persistente possui 14 distritos (15,6\% do total). Na década de 1990, esse Grupo perdeu 119.848 habitantes e, na década de 2000, essa perda foi de 48.165 habitantes. Ao longo dessas duas décadas, o Grupo 1 perdeu um total de 168.013 habitantes.

0 Grupo 2 da inversão demográfica possui 38 distritos (39,6\% do total). É o Grupo de maior interesse para o presente artigo. Na década de 1990, esse Grupo perdeu 342.541 habitantes e, na década de 2000, ganhou 243.922 habitantes. Entre essas perdas e ganhos, restou uma diferença de 98.619 habitantes. Portanto, apesar de importante, a inversão demográfica e o "repovoamento" do centro expandido ainda não foram suficientes para recuperar 0 patamar populacional que aqueles distritos detinham no final da década de 1990.

0 Grupo 3 da "periferização" persistente possui 39 distritos (40,6\% do total). Também é um Grupo de grande interesse para os estudos. Na década de 1990, os distritos desse Grupo ganharam 1.184.444 habitantes e, na década de 2000, ganharam mais 631.354 habitantes. Apesar do evidente arrefecimento no crescimento populacional associado com a "periferização", ainda houve um saldo positivo de 553.090 habitantes nos distritos daquele Grupo.

0 Grupo 4 do esvaziamento periférico possui somente 4 distritos (4,2\% do total). Os distritos desse pequeno Grupo ganharam 67.306 habitantes na década de 1990 e perderam 9.154 moradores na década de 2000. Entre ganhos e perdas populacionais, esse Grupo ficou ainda com um saldo positivo de 58.152 habitantes. 
Figura 3 - Distribuição dos Grupos 1, 2, 3 e 4

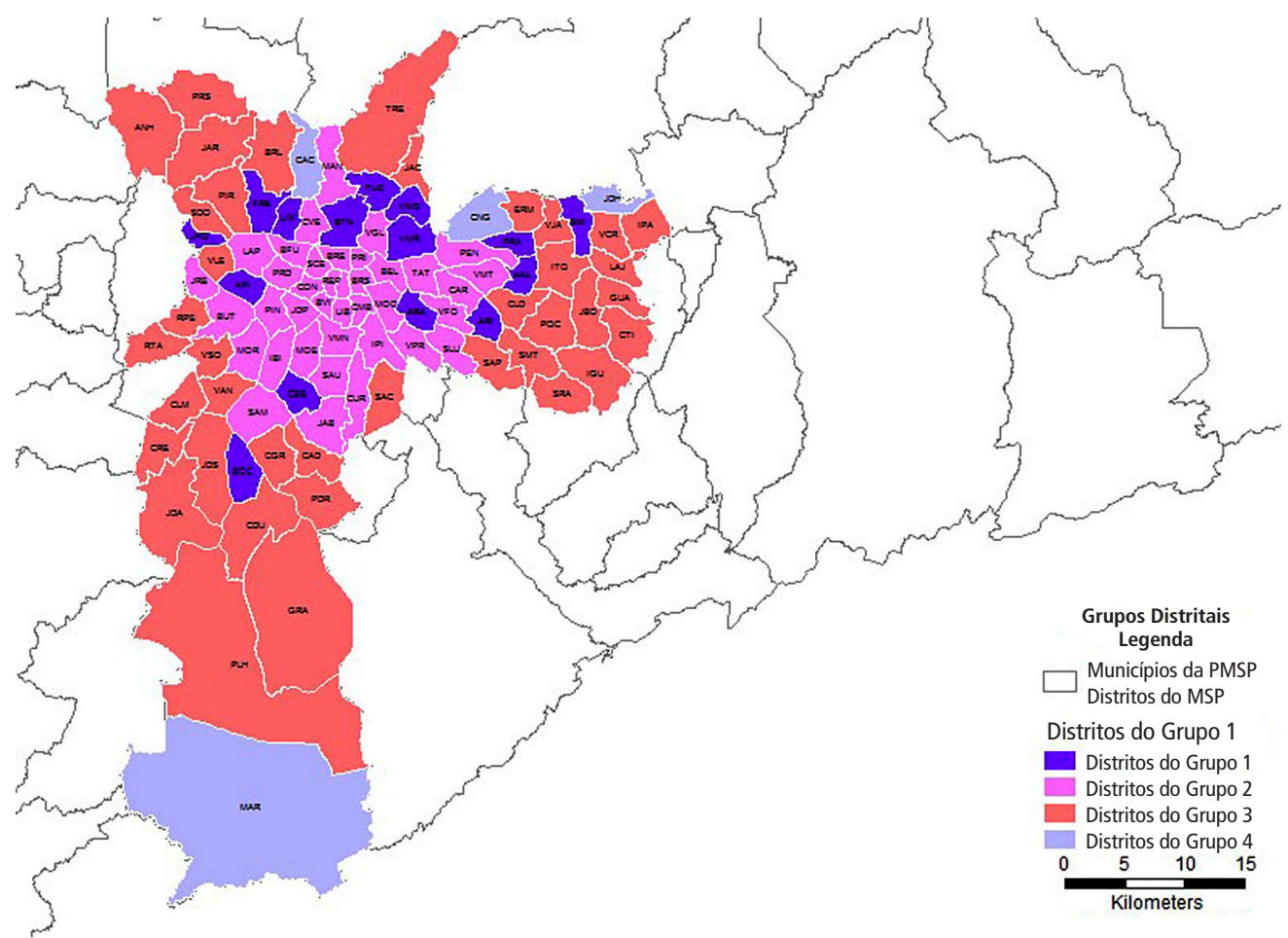

Fontes: Censos demográficos IBGE de 1991, 2000 e 2010.

0 mapa da Figura 3 mostra a localização dos distritos inseridos em cada um desses Grupos. Percebe-se claramente a predominância dos Grupos 2 e 3 que, juntos, englobam 77 distritos (80,2\% dos 96 distritos paulistanos) e abrangem a maior parte da área urbanizada do município de São Paulo.

Considerando o objetivo principal do presente artigo, qual seja, analisar e discutir as desigualdades habitacionais associadas ao "repovoamento" do centro expandido, propõe-se enfocar os estudos nos quatro grupos distritais com ênfase no Grupo 2 cujos distritos constituem aquele centro expandido que passou por "repovoamento" recente.

\section{A falta de política habitacional de interesse social no centro expandido do município de São Paulo}

0 "repovoamento" do centro expandido do município de São Paulo ocorrido entre os anos 2000 e 2010 associou-se à grande produção de empreendimentos imobiliários residenciais verticais ocorrida naquele mesmo período, conforme sugerido por Marques e Requena (2015). A análise a respeito dessa associação foi aprofundada em outro trabalho elaborado pelo autor (Nakano, 2015). 
Para quantificar essa produção imobiliária destinada a adquirentes de média e alta renda, optou-se por trabalhar os dados relativos aos lançamentos de empreendimentos imobiliários residenciais verticais ${ }^{12}$ lançados no período de 1998 e 2008, levando-se em conta indicação de Aranha e Torres (2014) em boletim da Fundação Seade sobre a relação entre crescimento demográfico e produção imobiliária nos distritos paulistanos. Tal indicação se baseou em estudo da Empresa Brasileira de Estudos sobre o Patrimônio (Embraesp), segundo o qual em "mais de $60 \%$ dos imóveis novos os prazos de entrega são superiores a 24 meses" (Embreaesp, 2013, apud Aranha e Torres, 2014, p. 7). Com base nessa constatação, aqueles autores adotaram um recorte temporal entre 1998 e 2007. No presente estudo, optamos por um recorte temporal um pouco diferente, entre 1998 e 2008, porque os empreendimentos imobiliários residenciais lançados a partir de 1998 podem ter sido entregues a partir de 2000 e boa parte dos empreendimentos lançados até 2008, com o mercado imobiliário plenamente aquecido, pode ter sido entregue até 2010.

A Tabela 1 mostra a quantidade de empreendimentos imobiliários residenciais verticais, com seus respectivos apartamentos, lançados entre 1998 e 2008 nos quatro grupos distritais descritos anteriormente. Nota-se que o Grupo 2, com os distritos do centro expandido onde ocorreu o "repovoamento" entre 2000 e 2010, recebeu a maior quantidade daqueles empreendimentos. 0 Grupo 3, que recebeu a segunda maior quantidade, teve menos que a metade de empreendimentos lançados em comparação com o Grupo 2. No que diz respeito ao número de apartamentos, tem-se o mesmo quadro.

Tabela 1 - Número de empreendimentos imobiliários residenciais verticais e de seus respectivos apartamentos lançados nos grupos distritais do município de São Paulo - 1998 e 2008

\begin{tabular}{c|c|c}
\hline $\begin{array}{c}\text { Grupos } \\
\text { Distritais }\end{array}$ & $\begin{array}{c}\mathbf{N}^{\circ} \text { de empreendimentos imobiliários residenciais } \\
\text { verticais lançados entre 1998 e 2008 }\end{array}$ & $\begin{array}{c}\text { Apartamentos em empreendimentos imobiliários } \\
\text { residenciais verticais lançados entre 1998 e 2008 }\end{array}$ \\
\hline Grupo 1 & 482 & 32.512 \\
Grupo 2 & 2.712 & 165.596 \\
Grupo 3 & 882 & 78.073 \\
Grupo 4 & 30 & 3.651 \\
\hline Total & 4.106 & 279.832 \\
\hline
\end{tabular}

Fonte: Empresa Brasileira de Estudos de Patrimônio (Embraesp), 1998 a 2008. 
Certamente, os apartamentos de 1, 2, 3 e 4 dormitórios produzidos nesses empreendimentos do Grupo 2, correspondentes a 59,2\% do total de apartamentos lançados no município de São Paulo entre 1998 e 2008, não foram destinados à população de baixa renda, pois os preços médios (no distrito) desses apartamentos, no momento de seus lançamentos, variaram de $R \$ 69.225,00$ (Brás) a $R \$ 1.197 .645,21$ (Morumbi).

Não faz parte do escopo do presente artigo aprofundar a relação entre o "repovoamento" e a produção de empreendimentos residenciais verticais no centro expandido do município de São Paulo. 0 importante é destacar o fato de que aquela produção imobiliária realizada por agentes do mercado formal de incorporação, destinada principalmente para adquirentes de média e alta renda, ocorreu concomitantemente com o aumento de moradias precárias em cômodos, cortiços e favelas ocupadas por populações de baixa renda, conforme descrito adiante.

As moradias em cômodos e em cortiços podem ser vistas como um dos meios comumente utilizados pelas populações de baixa renda para acessar as moradias localizadas, geralmente, em áreas centrais das cidades que, apesar de bem localizadas, apresentam alternativas habitacionais que, de certo modo, cabem em baixos orçamentos familiares. Em geral, a ocupação desses cômodos e cortiços ocorre mediante o pagamento de aluguéis, nem sempre baratos, que pesam nos orçamentos daquelas pessoas que lutam diariamente para auferir rendimentos os quais, não raramente, são insuficientes para satisfazer suas necessidades básicas.
No centro expandido do município de São Paulo, esses cômodos e cortiços podem estar em diferentes tipos de construções, localizadas, por exemplo, na Barra Funda, Bela Vista, Bom Retiro, Brás, Campos Elíseos, Glicério, Lapa, Liberdade, Mooca, Morumbi, Pari, República, Santa Ifigênia, Saúde, Sé, Vila Prudente, dentre outros distritos. Aqueles tipos de domicílios podem estar nos miolos de quadras e dispostos em fileiras construídas ao longo de terrenos profundos, paralelas a estreitos corredores de acesso, dentre outras situações. Podem ainda estar no interior de cômodos ou em "puxadinhos" de imóveis antigos deteriorados, como os antigos casarões que um dia serviram de moradia a famílias endinheiradas. Ou, então, podem se localizar em favelas que, por razões diversas, resistiram a processos de remoção e de erradicação e assim permaneceram em locais do centro expandido como Heliópolis e Paraisópolis, as duas maiores favelas paulistanas. Desse modo, os cômodos e cortiços e alguns assentamentos precários paulistanos podem estar próximos aos polos de empregos, aos comércios e serviços diversificados, aos bairros das camadas de alta renda, aos sistemas de transporte coletivo e às provisões de serviços, equipamentos e infraestruturas urbanas.

Desde o início do século XX, os cômodos e cortiços do município de São Paulo colocaram-se como alternativa de moradia para a população de baixa renda. É uma alternativa que persiste até hoje na cidade, ainda que os moradores se encontrem em situação instável, pois podem ser despejados a qualquer momento, sem maiores explicações. Já foram objetos de estudos de pesquisadores como, por exemplo, Kohara (2009), que analisou a relação entre 0 
(mau) desempenho escolar das crianças moradoras de cortiços localizados no Glicério, área do centro antigo paulistano. Piccini (2004) também estudou as diferentes visões sobre os cortiços de São Paulo, descrevendo as estratégias de intervenção levadas a cabo por distintos agentes do poder público.

Os cômodos e cortiços existentes no centro expandido paulistano mostram a falta que faz não ter uma política urbana e habitacional que promova a inclusão social das populações de baixa renda em condições mais adequadas de moradia em áreas bem localizadas da cidade, mais bem servidas por ofertas de emprego, transportes coletivos, serviços, equipamentos e infraestruturas urbanas. Esses cômodos e cortiços evidenciam a luta que a população de baixa renda, com condições socioeconômicas minimamente suficientes para pagar os aluguéis, realiza cotidianamente para viver nessas áreas mais valorizadas ao invés de irem morar em locais da periferia. As condições socioeconômicas dessa população permitem, mesmo em situação instável, a proximidade com oportunidades e benefícios da vida urbana que não são encontradas na periferia; além disso, os moradores da periferia gastam mais com transportes nas suas idas e vindas entre os locais de moradia e de trabalho, estudo, consumo, entre outros.

Apesar de representarem uma pequena parcela do total de domicílios do município de São Paulo, ${ }^{13}$ os cômodos e cortiços devem ser vistos como uma das faces em atrito cada vez mais acirrado na luta pelos acessos ao centro expandido no contexto do seu "repovoamento", verificado com a inversão demográfica ocorrida no Grupo 2, conforme descrito anteriormente. É na perspectiva desse atrito socioespacial que devemos observar os dados, apresentados na Tabela 2, sobre a evolução no número de domicílios em cômodos e cortiços nos grupos distritais caracterizados anteriormente, a partir das tendências demográficas ocorridas na virada do século XX para o XXI.

Tabela 2 - Evolução no número de domicílios em cômodos e cortiços segundo grupos distritais do município de São Paulo - 2000 a 2010

\begin{tabular}{c|c|c|c|c}
\hline \multirow{2}{*}{$\begin{array}{c}\text { Grupos } \\
\text { Distritais }\end{array}$} & 2000 & 2010 & $\begin{array}{c}\text { Variação } \\
\text { em n's absolutos }\end{array}$ & Variação percentual \\
\cline { 2 - 5 } & 4.329 & 3.890 & -439 & $-10,1$ \\
\hline Grupo 1 & 11.069 & 15.222 & 4.153 & 37,5 \\
Grupo 2 & 28.904 & 22.111 & -6.793 & $-23,5$ \\
Grupo 3 & 1.701 & 1.699 & -2 & $-0,1$ \\
Grupo 4 & 46.003 & 42.922 & -3.081 & $-6,7$ \\
\hline
\end{tabular}

Fonte: Censos demográficos IBGE de 2000 e 2010. 
Chama a atenção o fato de que o Grupo 2 foi o único a ter aumento de domicílios em cômodos e cortiços (37,5\%), com destaque para os distritos Barra Funda, Cambuci, Jaguaré, Morumbi, Santa Cecília e Vila Prudente, que tiveram aumento de mais de $300 \%$ (no Morumbi esse aumento foi maior do que $900 \%)$. Como visto, os distritos desse Grupo 2 são os que se localizam no centro expandido da cidade e que sofreram a inversão demográfica caracterizada pela perda populacional, na década de 1990, e pelo ganho na de 2000. Os Grupos 1, 3 e $4,{ }^{14}$ assim como o município de São Paulo como um todo, registraram redução no número desse tipo de domicílio precário. Isso mostra que a população de baixa renda participa do repovoamento e da inversão demográfica no centro expandido de São Paulo através do acesso às moradias precárias inscritas em cômodos e cortiços.

Outras faces daquele atrito entre a produção de empreendimentos imobiliários residenciais verticais com apartamentos destinados a adquirentes de média e alta renda e as moradias das populações de baixa renda aparecem nas favelas localizadas no centro expandido, próximas aos bairros com moradores mais ricos. Aquele atrito é candente no caso das favelas que se encontram em bairros que receberam grande quantidade de empreendimentos residenciais verticais.

Em que pesem as conhecidas limitações dos dados referentes aos domicílios em setores censitários classificados como aglomerados subnormal pelo IBGE, ainda vale utilizá-los como uma aproximação para verificar a magnitude dos aumentos nos números de domicílios em assentamentos precários localizados nos distritos do Grupo 2 inseridos no centro expandido. Mais importante do que os números absolutos, importa observar as variações ocorridas entre 2000 e $2010^{15}$ que mostraram as tendências relativas a essa modalidade de provisão habitacional utilizada predominantemente pela população de baixa renda para se inserir precariamente nas localizações urbanas centrais e periféricas da cidade.

Na Tabela 3, nota-se clara tendência, nos grupos distritais e no município de São Paulo como um todo, de crescimento nos números daqueles domicílios localizados principalmente em favelas e loteamentos irregulares. Em termos percentuais, esse aumento foi maior no contexto do "repovoamento" do centro expandido, impulsionado pela inversão demográfica verificada nos distritos do Grupo 2 (74,6\%). Isso não significa que os avanços dos domicílios em assentamentos precários associados à "periferização" persistente foram insignificantes. Pelo contrário, tais avanços ocorridos nos distritos do Grupo 3 foram muito significativos, tanto em números absolutos (112.640 domicílios) quanto relativos $(59,5 \%)$.

É fácil verificar a ocorrência dos aumentos no número de moradores e de domicílios nas favelas centrais e periféricas existentes quando se percebem a verticalização visível das suas construções e o adensamento dos seus espaços internos. Assim, não é errado afirmar que o "repovoamento" do centro expandido do município de São Paulo, associado à inversão demográfica ocorrida nessa parte do município de São Paulo inserida no Grupo 2 durante a passagem da década de 1990 para a de 2000, foi associado a aumentos nos números de domicílios em cômodos e cortiços, bem como em assentamentos precários. 
Tabela 3 - Evolução no número de domicílios em aglomerados subnormais segundo grupos distritais do município de São Paulo - 2000 a 2010

\begin{tabular}{|c|c|c|c|c|}
\hline \multirow{2}{*}{$\begin{array}{l}\text { Grupos } \\
\text { Distritais }\end{array}$} & \multicolumn{4}{|c|}{ Domicílios em aglomerados subnormais } \\
\hline & 2000 & 2010 & $\begin{array}{c}\text { Variação em ns } \\
\text { absolutos - } 2000 \text { a } 2010\end{array}$ & $\begin{array}{c}\text { Variação Percentual - } \\
2000 \text { a } 2010\end{array}$ \\
\hline Grupo 1 & 10.166 & 13.382 & 3.216 & 31,6 \\
\hline Grupo 2 & 14.202 & 24.800 & 10.598 & 74,6 \\
\hline Grupo 3 & 189.459 & 302.099 & 112.640 & 59,5 \\
\hline Grupo 4 & 13.407 & 15.475 & 2.068 & 15,4 \\
\hline Total & 227.234 & 355.756 & 128.522 & 56,6 \\
\hline
\end{tabular}

Fonte: Censos demográficos IBGE de 2000 e 2010.

São as camadas populares de baixa renda "surfando" na onda do "repovoamento" do centro expandido e da inversão demográfica para se inserir, precariamente, nas áreas melhor localizadas da cidade de São Paulo. Porém, essas camadas populares não deslizam tranquilamente nessa onda. Aquele "repovoamento" do centro expandido guarda conflitos entre as duas formas de provisão habitacional voltadas, de um lado, para a população de baixa renda (cômodos, cortiços e assentamentos precários) e, de outro lado, para a população de média e alta renda (empreendimentos residenciais verticais produzidos pelo mercado imobiliário formal).

Também não é exagerado supor que essa tendência provoca fricções sociais crescentes nas partes mais dinâmicas da cidade de São Paulo. Tais fricções evidenciam a falta que faz não ter políticas urbanas e habitacionais baseadas na inclusão social e territorial da população de baixa renda no interior do "repovoamento" e da inversão demográfica verificada nos distritos do Grupo 2 inseridos no centro expandido do município de São Paulo. Caso essas políticas não venham a correr em um futuro não muito distante, essas fricções podem se tornar fraturas sociais expostas.

\section{As ações políticas dos movimentos populares na luta por habitação de interesse social no centro expandido do município de São Paulo}

Na década de 1990, quando se dizia que as áreas centrais da cidade de São Paulo se encontravam deterioradas, surgiram iniciativas por parte de grupos econômicos poderosos que se articularam para defender uma agenda de requalificação urbana baseada, por exemplo, em melhorias de espaços públicos, implantação de equipamentos culturais delineados segundo 
valores e práticas burguesas, ações de zeladoria urbana, renovações de infraestruturas, entre outros itens. ${ }^{16}$ Apesar de não abertamente declaradas, tais iniciativas buscavam requalificar os espaços urbanos gerando condições favoráveis à valorização do patrimônio imobiliário, às oportunidades para realização e apropriação privada da renda fundiária, à realização de negócios empresariais e à atração de investimentos empresariais. Em vários aspectos, essas iniciativas possuíam características socialmente excludentes e antipopulares. ${ }^{17}$

Em contraponto àquela iniciativa de cunho elitista, a sociedade paulistana viu o surgimento de uma nova agenda urbana para as áreas centrais de São Paulo alinhada com o ideário do direito à cidade. Essa agenda urbana se tornou nacionalmente visível a partir das ocupações de prédios ociosos localizados naquelas áreas centrais, realizadas por líderes e militantes de movimentos de luta por moradia. Tais ocupações foram vistas, por um lado, como ações políticas para a reivindicação de moradias adequadas e bem localizadas na cidade e, por outro lado, como violações do direito de propriedade. Trata-se de ações previamente planejadas que tiveram grande repercussão nos meios de comunicação de massa de expressão nacional.

Foi na década de 1990 que surgiram, no município de São Paulo, os movimentos populares de luta por moradia que reivindicavam explicitamente a promoção da habitação de interesse social nas áreas centrais da cidade. Nesse período, surgiu o Movimento dos Sem Teto do Centro (MSTC), a União de Luta dos Cortiços e Moradia (ULC), o Movimento de Moradia da Região Central (MMRC) e o Fórum de Cortiços (FC). Na década seguinte, de 2000, surgiram outros movimentos populares similares que também atuavam nas áreas centrais da cidade e utilizavam a ocupação de imóveis ociosos, públicos e privados, como formas de pressão e de ação política. Aqueles movimentos de luta por moradia atuantes nas áreas centrais do município de São Paulo continuam ativos e convivem com esses novos movimentos do centro que precisam ser estudados com maiores detalhes e profundidade, pois, apesar das similaridades, certamente apresentam diferenças, algumas vezes conflitos, em relação aos movimentos surgidos na década de 1990.

O Quadro 1 mostra os números de ocupações de prédios ociosos localizados nas áreas centrais do município de São Paulo que foram realizadas por movimentos de luta por moradia no período entre 1997 e 2012. Nota-se que somente em 2008 não houve nenhuma ocupação de imóvel ocioso nessas áreas. Vale dizer que alguns desses imóveis ociosos foram ocupados mais de uma vez, após a realização de ações de integração de posse solicitadas pelos proprietários. Muitas dessas ocupações perduram por anos a fio e algumas resistem até os dias de hoje.

Com aquelas ações políticas, os chamados movimentos de luta por moradia do centro de São Paulo não reivindicavam somente habitação de interesse social acessível para a população de baixa renda. Reivindicavam também ações públicas que fizessem com que essa habitação estivesse implantada em uma localização urbana a partir da qual os moradores pudessem ter acessos às provisões de empregos e de todos os serviços, equipamentos e infraestruturas urbanas básicas de transporte coletivo, saneamento básico, saúde, educação, assistência social, cultura, lazer, entre outros. 
Quadro 1 - Número de ocupações de imóveis ociosos localizados nas áreas centrais do município de São Paulo realizadas por movimentos de luta por moradia - 1997 e 2012

\begin{tabular}{|c|c|}
\hline Ano & $\begin{array}{c}\text { Número de ocupações de imóveis ociosos nas áreas } \\
\text { centrais do município de São Paulo realizadas por } \\
\text { movimentos de luta por moradia }\end{array}$ \\
\hline 1997 & 11 \\
1998 & 2 \\
1999 & 18 \\
2000 & 7 \\
2001 & 6 \\
2002 & 8 \\
2003 & 8 \\
2004 & 11 \\
2005 & 5 \\
2006 & 4 \\
2007 & 4 \\
2008 & 0 \\
2009 & 1 \\
2010 & 6 \\
2011 & 9 \\
2012 & 11 \\
\hline
\end{tabular}

Fonte: Sanches (2014, pp. 461-463).

Obs.: as ocupações de imóveis ociosos listadas por Sanches localizam-se nos distritos de Barra Funda, Bela Vista, Belém, Bom Retiro, Brás, Carrão, Consolação, Ipiranga, Liberdade, Mooca, Pari, Perdizes, República, Santa Cecília, Sé e Tatuapé.

Assim, os movimentos de moradia do centro de São Paulo colocavam o direito à cidade articulado com o direito à moradia digna na pauta de reivindicações políticas endereçadas para a sociedade como um todo, especialmente para diferentes instâncias do Estado brasileiro responsáveis pela formulação e implementação de políticas urbanas e habitacionais. Enfim, reivindicavam habitação e, junto com ela, a inclusão na cidade.

\section{Considerações finais}

Como consideração final, vale destacar, a despeito das mudanças na distribuição espacial da população paulistana, a permanência das desigualdades de renda (que se relacionam com outras dimensões das desigualdades sociais) estruturadas na persistência do modelo centro-periferia que ainda caracteriza os espaços intraurbanos do município de São Paulo. 
Vale destacar, ainda, a existência de uma tendência de valorização da vida e da experiência urbana expressa no "repovoamento" do centro expandido e na inversão demográfica que envolve diferentes classes sociais que buscam acessar moradias em localizações mais centrais e vantajosas do ponto de vista das relações com os locais de trabalho, consumo, educação, entre outras oportunidades da vida urbana. Os meios que são utilizados por essas classes sociais para acessar essas moradias e localizações urbanas mais bem qualificadas passam pelas diferentes frações do mercado fundiário e imobiliário, do formal ao informal. As políticas públicas, urbana e habitacional, não têm ajudado na criação de acessos àquelas moradias e localizações urbanas principalmente para as populações mais vulneráveis e de menor renda.

A tendência mais equilibrada de distribuição espacial da população paulistana, a diminuição da pressão demográfica trazida pelo arrefecimento no ritmo de crescimento populacional e a valorização da vida e experiência urbana por parte de diferentes grupos sociais que buscam, nas cidades, os acessos às "geografias de oportunidades", colocam grandes desafios de ordem política, econômica, territorial e ambiental. Só o tempo dirá se o município de São Paulo e sua região metropolitana conseguirão responder à altura essas condições favoráveis para o desenvolvimento humano e social.

\section{Anderson Kazuo Nakano}

Universidade Federal de São Paulo, Instituto das Cidades. São Paulo, SP/Brasil. kazuo.nakano@gmail.com

\section{Notas}

(1) No presente artigo, considera-se, como centro expandido do município de São Paulo, os distritos que registraram reduções populacionais na década de 1990 e passaram a registrar aumentos populacionais na década de 2000. Esses distritos são: Barra Funda, Bela Vista, Belém, Bom Retiro, Brás, Butantã, Cambuci, Carrão, Casa Verde, Consolação, Cursino, Ipiranga, Itaim Bibi, Jabaquara, Jaguaré, Jardim Paulista, Lapa, Liberdade, Mandaqui, Moema, Mooca, Morumbi, Pari, Penha, Perdizes, Pinheiros, República, Santa Cecília, Santo Amaro, São Lucas, Saúde, Sé, Tatuapé, Vila Formosa, Vila Guilherme, Vila Mariana, Vila Matilde e Vila Prudente. Os 96 distritos do município de São Paulo foram instituídos pela lei municipal n. 11.220/1992.

(2) Esse fenômeno está explícito na iniciativa do governo do estado de São Paulo chamada "PPP da Habitação" cujo objetivo é promover acesso a imóveis localizados nas áreas centrais do município para empresas privadas executarem empreendimentos habitacionais de interesse social. 
(3) Nas discussões sobre a provisão de novas habitações de interesse social para as populações de baixa renda em áreas centrais das grandes cidades brasileiras, notadamente para aquelas com renda familiar de até três salários mínimos que integram cerca de $90 \%$ do déficit habitacional do País, é comum ouvir a expressão "a conta não fecha". Com essa expressão se diz que os altos custos de terrenos localizados naquelas áreas centrais aumentam os custos de produção de empreendimentos imobiliários inviabilizando a sua comercialização para compradores que não têm poder aquisitivo suficiente que permita a cobrança de um preço que garanta as margens de lucro almejadas pelo empreendedor. Com isso, a lógica mercantil exclui as populações de baixa renda do acesso à moradia em áreas centrais das cidades. É por isso que as discussões, propostas e experiências baseadas em programas de aluguéis habitacionais subsidiados ganham força em várias cidades do Brasil e da América Latina.

(4) Em seu recente livro, intitulado Cidades rebeldes - do direito à cidade à revolução urbana, Harvey (2014) mencionou a "incapacidade de os direitos de propriedade privada individualizada atenderem aos interesses comuns" (p. 147) e, por isso, defende a necessidade de estabelecer bens e propriedades comuns nas cidades dissociados dos processos de mercantilização.

(5) A Estrada de Ferro Santos-Jundiaí foi a primeira ferrovia do estado de São Paulo construída, em 1867, pela companhia inglesa São Paulo Railway. Ligava as fazendas produtoras de café do interior paulista ao porto de Santos, principal ponto de recebimento de importações e escoamento de exportações.

(6) As taxas geométricas de crescimento anuais eram: (1) Município de São Paulo (MS) - 1,2\% na década de 1980 e 0,9\% na década de 1990; (2) Região Metropolitana de São Paulo (RMSP) 1,9\% na década de 1980 e 1,6\% na década de 1990. Vale dizer que a tendência de queda nessas taxas continua na década de 2000 quando o MSP registrou taxa de 0,7\% e a RMSP de 0,9\%.

(7) Água Rasa, Alto de Pinheiros, Aricanduva, Artur Alvim, Campo Belo, Freguesia do Ó, Jaguara, Limão, Ponte Rasa, Santana, São Miguel, Socorro, Tucuruvi e Vila Medeiros.

(8) Barra Funda, Bela Vista, Belém, Bom Retiro, Brás, Butantã, Cambuci, Carrão, Casa Verde, Consolação, Cursino, Ipiranga, Itaim Bibi, Jabaquara, Jaguaré, Jardim Paulista, Lapa, Liberdade, Mandaqui, Moema, Mooca, Morumbi, Pari, Penha, Perdizes, Pinheiros, República, Santa Cecília, Santo Amaro, São Lucas, Saúde, Sé, Tatuapé, Vila Formosa, Vila Guilherme, Vila Mariana, Vila Matilde e Vila Prudente.

(9) Anhanguera, Brasilândia, Campo Grande, Campo Limpo, Capão Redondo, Cidade Ademar, Cidade Dutra, Cidade Líder, Cidade Tiradentes, Ermelino Matarazzo, Grajaú, Guaianases, Iguatemi, Itaim Paulista, Itaquera, Jaçanã, Jaraguá, Jardim Angela, Jardim São Luís, José Bonifácio, Lajeado, Parelheiros, Parque do Carmo, Pedreira, Perus, Pirituba, Raposo Tavares, Rio Pequeno, Sacomã, São Domingos, São Mateus, São Rafael, Sapopemba, Tremembé, Vila Andrade, Vila Curuçá, Vila Jacuí, Vila Leopoldina e Vila Sonia.

(10) No presente artigo, adota-se o termo "periferização" em sintonia com os estudos realizados nas décadas de 1970 e 1980 que mostraram as especificidades do "padrão periférico de urbanização" que caracterizou e continua a marcar as cidades brasileiras. Trata-se, por exemplo, dos estudos realizados por Camargo et al. (1975), Maricato (1982), Rolnik e Bonduki (1982), entre outros.

(11) Cachoeirinha, Cangaíba, Jardim Helena e Marsilac. 
(12) Foram considerados empreendimentos imobiliários residenciais verticais aqueles com 4 ou mais pavimentos.

(13) Segundo o Censo de 2010, o município de São Paulo tinha 43 mil domicílios em cômodos e cortiços em um total de 3,6 milhões de domicílios.

(14) As variações dos dados referentes ao Grupo 4 devem ser consideradas com restrições por causa do seu baixo valor e do fato de que estamos trabalhando com os microdados da amostra dos censos demográficos do IBGE.

(15) Os ajustes realizados no Censo Demográfico 2010 pelo IBGE, com a reclassificação de setores censitários como aglomerados subnormais a partir de semelhanças nas características urbanísticas e socioeconômicas, não devem ter afetado de modo significativo os setores censitários classificados como aglomerado subnormal localizados no centro expandido do município de São Paulo.

(16) No caso da cidade de São Paulo, tal iniciativa levou, por exemplo, à criação da Associação Viva o Centro e da Associação Paulista Viva que contaram com o apoio do poder público em vários momentos e reuniram, por exemplo, grupos de empresários dos setores comerciais e financeiros, igreja católica, profissionais liberais, grandes proprietários de imóveis, entre outros.

(17) Para uma análise crítica sobre as ações e coalizões empresariais, inclusive com envolvimento do poder público, que operaram na década de 1990 em áreas valorizadas da cidade de São Paulo, as quais concentravam e ainda concentram polos de escritórios, atividades terciárias diversificadas, dentre outras funções centrais, ver os trabalhos de Fix (2001) e Frúgoli (2006). Os trabalhos desses autores mostraram que, por trás daquelas ações e coalizões, encontravamse grupos econômicos privados interessados principalmente nas valorizações e oportunidades imobiliárias relativas àquelas áreas centrais.

\section{Referências}

ARANHA, V. e TORRES, H. da G. (2014). Lançamentos imobiliários e dinâmica demográfica recentes no Município de São Paulo. 1a Análise. São Paulo, Seade, n. 15.

CAMARGO, C. P. F. et al. (1975). São Paulo 1975 - crescimento e pobreza. São Paulo, Loyola.

FIX, M. (2001). Parceiros da exclusão. São Paulo, Boitempo.

FRÚGOLI, H. (2006). Centralidade em São Paulo. São Paulo, Edusp.

HARVEY, D. (2014). Cidades rebeldes - do direito à cidade à revolução urbana. São Paulo, Martins Fontes.

JANUZZI, P. e JANUZZI, N. (2002). Crescimento urbano, saldos migratórios e atratividade residencial dos distritos da cidade de São Paulo: 1980-2000. Revista Brasileira de Estudos Urbanos e Regionais, v. 4, n. 1-2, pp. 107-127.

KOHARA, L. T. (2009). Relação entre as condições da moradia e o desempenho escolar: estudo com crianças residentes em cortiços. Tese de Doutorado. São Paulo, Universidade de São Paulo. 
MARICATO, E. (1982). “Autoconstrução, arquitetura possível”. In: MARICATO, E. (org.). A produção capitalista da casa (e da cidade) no Brasil industrial. São Paulo, Alfa Omega.

MARQUES, E. e REQUENA, C. (2015). “Trajetórias demográficas diversas e heterogeneidade". In: MARQUES, E. (org.). A metrópole de São Paulo no século XXI-espaços, heterogeneidades e desigualdades. São Paulo, Editora Unesp.

NAKANO, A. K. (2015). Elementos demográficos sobre a densidade urbana na produção imobiliária: São Paulo, uma cidade oca? Tese de Doutorado. Campinas, Universidade Estadual de Campinas.

PICCINI, A. (2004). Cortiços na cidade - conceitos e preconceitos na reestruturação do centro urbano de São Paulo. São Paulo, Annablume.

ROLNIK, R. e BONDUKI, N. (1982). "Periferia da Grande São Paulo - reprodução do espaço como expediente de reprodução de força de trabalho". In: MARICATO, E. (org.). A produção capitalista da casa (e da cidade) no Brasil industrial. São Paulo, Alfa Omega.

SANCHES, D. (2014). Processo participativo como instrumento de moradia digna - avaliação dos projetos da área central de São Paulo - 1990-2012. Tese de Doutorado. São Paulo, Universidade Presbiteriana Mackenzie.

TORRES, H. da G. (2005). “A fronteira paulistana”. In: MARQUES, E. e TORRES, H. da G. (orgs.). São Paulo - segregação, pobreza e desigualdades sociais. São Paulo, Senac.

VILLAÇA, F. (2001). Espaço intraurbano no Brasil. São Paulo, Fapesp/Studio Nobel/Lincoln Institute of Land Policy.

Texto recebido em 17/set/2017

Texto aprovado em 5/dez/2017 